\title{
Use of theoretical efficiencies of protein and fat synthesis to calculate energy requirements for growth in pigs
}

\author{
Carl Z. Roux* \\ Department of Genetics, University of Pretoria, Pretoria 0002, South Africa \\ (Received 30 October 2007 - Revised 10 April 2008 - Accepted 11 April 2008 - First published online 7 August 2008)
}

From the observation that fasting heat production includes the cost of body protein resynthesis and the evidence that protein resynthesis is included in the regression estimate of protein retention efficiency it is conjectured that the estimate of maintenance from fasting heat production must be conceptually equal to the regression intercept estimate of maintenance plus the cost of body protein resynthesis. Experimental evidence for comparable situations shows an approximate observational equality in agreement with the conjectured conceptual equality. This approximate equality implies that the theoretical (stiochiometric) efficiency of protein synthesis should be used in conjunction with the estimate of maintenance from fasting heat production for the prediction of growth energy requirements. The approximate maintenance equalities suggest furthermore approximate equality of theoretical fat synthesis efficiency and regression fat retention efficiency. This conjecture is also supported by experimental evidence. Some practical nutrition and pig breeding implications of the foregoing conclusions are indicated.

Estimation of energy requirements: Estimation of maintenance: Fasting heat production

The factorial model proposed by Kielanowski ${ }^{(1)}$ describes metabolisable energy (ME) utilisation as the sum of three factors, namely maintenance, the total cost of protein retention (PR) and the total cost of fat retention (FR). It follows that in a regression context maintenance can be estimated by the intercept (INT) in the simple regression relationship between ME intake (MEI) and energy retention (ER) or the INT in the multiple regression relationship between MEI and both PR and FR. As energy balance does not necessarily imply both protein and fat balance ${ }^{(2)}$, these INT are not necessarily identical. However, estimates of the two possible INT may not differ much, as indicated by a comparison between regression estimates from Tables 1.11 and 1.12 by the Agricultural Research Council (ARC) ${ }^{(2)}$.

A third possibility for the estimation of maintenance is from a measurement of fasting heat production (HP), scaled by the efficiency of the utilisation of ME below maintenance. It is the purpose of the present paper to show that INT estimates of maintenance agree with fasting HP estimates if they are supplemented with estimates of the cost of body protein resynthesis. This finding is in agreement with the hypothesis that the ordinary regression estimate of PR efficiency $\left(k_{\mathrm{P}}\right)$ is deflated by the effects of body protein resynthesis. It also implies that the fasting HP estimate of maintenance should be used in conjunction with the theoretical (stoichiometric) efficiency of protein synthesis (PS).
From the foregoing approximate equalities one would expect that regression estimates of FR efficiency $\left(k_{\mathrm{F}}\right)$ should be approximately equal to theoretical estimates of fat synthesis efficiency. Experimental evidence confirms this conjecture.

\section{Theory and methods}

Turnover-related protein retention efficiency

Taking turnover into account, $k_{\mathrm{P}}$ can be defined ${ }^{(3)}$ as:

$$
k_{\mathrm{P}}=22.6 \mathrm{PR} /(22.6 \mathrm{PR}+3.766 \mathrm{PS}),
$$

where $\mathrm{PR}$ is in $\mathrm{kg} / \mathrm{d}$ and $\mathrm{PS}$ corresponds to the given rate of PR, allowing for turnover. The coefficient 22.6 represents the energy equivalent of protein $(\mathrm{MJ} / \mathrm{kg})$ and 3.766 the cost of synthesis based on the assumption that $5 \mathrm{~mol}$ ATP will arrange $1 \mathrm{~mol}$ of peptide bonds. Whittemore et al. ${ }^{(4)}$ give an equivalent definition with coefficients of 23.6 and 3.92.

For ease in application, PR and PS will be measured in energy units (MJ/d). It follows that equation (1) becomes:

$$
k_{\mathrm{P}}=\mathrm{PR} /(\mathrm{PR}+\mathrm{PS} / 6) \text {. }
$$

If there is no turnover, $\mathrm{PR}=\mathrm{PS}$ and $k_{\mathrm{P}}=6 / 7=0 \cdot 86$, given as theoretical (stoichiometric) value in texts such as Blaxter ${ }^{(5)}$.

It is customary to partition MEI into energy intake devoted to maintenance (IM), PR (IPR) and FR, all measured in terms

Abbreviations: ARC, Agricultural Research Council; CP, crude protein; DE, digestible energy; ER, energy retention; FR, fat retention; HP, heat production; $\mathrm{IM}$, intake devoted to maintenance; INT, intercept; IPR, intake devoted to protein retention; $k_{\mathrm{F}}$, fat retention efficiency; $k_{\mathrm{M}}$, maintenance efficiency; $k_{\mathrm{P}}$, protein retention efficiency; ME, metabolisable energy; MEI, metabolisable energy intake; PB, protein breakdown; PR, protein retention; PS, protein synthesis; $W$, live body mass.

* Corresponding author: Professor Carl Z. Roux, fax +27 12362 5327, email ina.goosen@up.ac.za 
of $\mathrm{MJ} / \mathrm{d}$, or represented in symbols by:

$$
\mathrm{MEI}=\mathrm{IM}+\mathrm{IPR}+\mathrm{IFR},
$$

where IFR is intake devoted to FR.

A popular model derived from equation (3) is expressed in the regression equation, also employed by the $\mathrm{ARC}^{(2)}$ :

$$
\mathrm{MEI}=\mathrm{INT}+\mathrm{PR} / k_{\mathrm{P}}+\mathrm{FR} / k_{\mathrm{F}},
$$

with INT representing the part of MEI devoted to maintenance.

It is axiomatic that the rate of PR is equal to the difference between the rate of PS and the rate of protein breakdown (PB):

$$
\mathrm{PR}=\mathrm{PS}-\mathrm{PB} \text {. }
$$

Then, from equations (2) and (5):

$$
\mathrm{PR} / k_{\mathrm{P}}=(7 / 6) \mathrm{PR}+\mathrm{PB} / 6,
$$

where $6 / 7$ is the theoretical (stoichiometric) efficiency of PS and $\mathrm{PB} / 6$ represents the cost of protein resynthesis. If equation (6) is substituted into equation (4), it follows that:

$$
\mathrm{MEI}=(\mathrm{INT}+\mathrm{PB} / 6)+(7 / 6) \mathrm{PR}+\mathrm{FR} / k_{\mathrm{F}} .
$$

A comparison between equations (3), (4) and (7) shows that two sets of possibilities exist for consideration, i.e.:

$$
\mathrm{IM}=\mathrm{INT} \text { and } \mathrm{IPR}=\mathrm{PR} / k_{\mathrm{P}}
$$

or:

$$
\mathrm{IM}=\mathrm{INT}+\mathrm{PB} / 6 \text { and } \mathrm{IPR}=(7 / 6) \mathrm{PR} .
$$

From the point of view of practical application both equations (8) and (9) may represent useful approximations. However, from a conceptual point of view there seems to be only one ultimate definition of maintenance, i.e. the intake at which both PR and FR are equal to zero. Algebraically both equations (8) and (9) represent such a conceptual point of zero retention maintenance. The only way to differentiate between equations (8) and (9) would, therefore, be on the basis of experimental evidence. However, obtaining both PR and FR equal to zero under experimental conditions may be very difficult to achieve as fat reserves may be used to fuel $\mathrm{PR}^{(2)}$. A practical alternative may be to approximate maintenance by the intake at zero ER. This can be done by deriving maintenance from fasting HP. Conventionally, maintenance derived from fasting HP is symbolically expressed as:

$$
\mathrm{IM}=\text { fasting } \mathrm{HP} / k_{\mathrm{M}},
$$

where $k_{\mathrm{M}}$ represents maintenance efficiency.

For easy reference, estimates of IM obtained by employing equation (9) will be denoted by $\mathrm{IM}_{\mathrm{I}}$ and $\mathrm{IM}$ estimated by employing equation (10) by $\mathrm{IM}_{\mathrm{H}}$.

It is general experience that the application of ordinary regression analysis to the estimation of $k_{\mathrm{P}}$ and $k_{\mathrm{F}}$ results in estimates of $k_{\mathrm{P}}$ that deviate markedly from the theoretical synthesis efficiency $6 / 7^{(5)}$, and that are approximately equal to an average value of $k_{\mathrm{P}}$ in equation (2). This average value of $k_{\mathrm{P}}$ is, in turn, dependent on average values of PR and PS determined by experimental feed intake levels ${ }^{(6,7)}$. HP at maintenance contains the heat loss due to PS involved in the turnover of body protein.
This corresponds to $\mathrm{PB} / 6$ in equation (6). Hence our central hypothesis is that the maintenance portion of equation (9) would be approximately equal to equation (10). The implied inequality between maintenance in equations (8) and (10) must, therefore, necessarily follow from the fact that in equation (8) $\mathrm{PB} / 6$ is accommodated in $k_{\mathrm{P}}$. In the final analysis the difference between equations (8) and (9) lies in the different allocation of $\mathrm{PB} / 6$ between maintenance and $k_{\mathrm{P}}$. Using the allocation in equation (9) has the advantage that it is unnecessary to estimate $k_{\mathrm{P}}$, as PS efficiency can be used in its place.

In geometrical terms the inequality between the maintenance terms in equations (8) and (9) arises from a curvilinear relationship between intake and PR which can be described by a variable tangent gradient defined by $1 / k_{\mathrm{P}}$ from equation (2). In ordinary linear regression this curvilinear relationship will be approximated by a straight line. This will cause no problem with extrapolation to maintenance for feed intakes near to maintenance. However, with even the lowest feeding levels in most pig efficiency experiments generally higher than half of ad libitum intake ${ }^{(6)}$, the linear approximation to a curvilinear relationship causes the underestimation of zero retention maintenance by the INT term in equation (4).

\section{Ignoring turnover in fat retention efficiency}

It is possible to define $k_{\mathrm{F}}$ in a similar fashion as $k_{\mathrm{P}}$ in equation (1). The coefficients involved would have to depend on the energy content of fat, diet composition as well as the proportion of body fat resynthesised from endogenous fat moieties. This notwithstanding, it is reasoned in the present communication that measurement error in ordinary regression estimates is of such magnitude that it would at present be impossible to distinguish between correspondence to $k_{\mathrm{F}}$ with or without turnover. Hence, I will proceed by showing that regression estimates are in satisfactory agreement with theoretical estimates of fat synthesis efficiency.

\section{Experimental evidence}

\section{Estimates of the cost of the resynthesis of existing protein}

Perhaps the most important requirement to test the hypothesis on the equivalence of the maintenance portion of equations (9) and (10) is estimation of the cost of resynthesis of existing body protein by $\mathrm{PB} / 6$. The most extensive measurements on whole-body breakdown rates for growing pigs are on threequarter Large White one-quarter Landrace female pigs ${ }^{(8,9)}$. Estimates from these sources ${ }^{(8,9)}$ are combined with estimates of INT and fasting $\mathrm{HP} / k_{\mathrm{M}}$ from the literature in Table 1.

The Meishan estimates are included in Table 1 to show that if breeds or experimental procedures are not carefully matched, widely divergent maintenance estimates can be obtained by the methods of equations (9) and (10). The agreement between the other estimates is remarkable, providing strong evidence that equations (9) and (10) should give similar answers under comparable circumstances.

The estimation of protein breakdown/6. On the assumption of a $6.25 \mathrm{~g} / \mathrm{g}$ conversion of $\mathrm{N}$ to protein and a gross energy content of protein of $23.6 \mathrm{~kJ} / \mathrm{g}$, the values of $\mathrm{PB} / 6$ from equation (5) for equally weighted treatment averages are $0.199\left(\mathrm{SE} 0.00650 ; n\right.$ 23) ${ }^{(8)}$ and $0.230(\mathrm{SE} 0.00878 ; n$ 32) 
Table 1. A comparison between estimates of maintenance requirement $\left(\mathrm{MJ} / \mathrm{kg}\right.$ live body mass $\left(W^{0.60}\right.$ per d) from intercepts (INT) corrected for protein resynthesis ${ }^{*}$ and from fasting heat production $(\mathrm{HP}) \dagger$

\begin{tabular}{lcc}
\hline & \multicolumn{2}{c}{ Type of estimate $\left(\mathrm{MJ} / \mathrm{kg} W^{0.60}\right.$ per d) } \\
\cline { 2 - 3 } & Corrected INT & Fasting HP \\
\hline Equation & $\mathrm{IM}=\mathrm{INT}+\mathrm{PB} / 6^{*}$ & $\mathrm{IM}=$ fasting $\mathrm{HP} / \mathrm{k}_{\mathrm{M}} \dagger$ \\
Type of pig & & \\
Large White & 1.285 & 1.289 \\
Pietrain & 1.205 & 1.230 \\
Meishan & 1.153 & 0.888 \\
Average pig (Western) & 1.069 & 1.071 \\
\hline IM, intake devoted to maintenance; & $\mathrm{PB}$, protein breakdown; $k_{\mathrm{M}}$, maintenance \\
efficiency. & & \\
*Equation (9). & & \\
†Equation (10). &
\end{tabular}

$\mathrm{MJ} / \mathrm{kg} W^{060}$ per $\mathrm{d}^{(9)}$, respectively, where $W$ indicates the live body mass of the animals. Weighted according to the number of observations in each experiment the average is:

$$
\mathrm{PB} / 6=0 \cdot 217 \mathrm{MJ} / \mathrm{kg} W^{0.60} \text { perd, }
$$

with SE 0.00579 , the value that will be accepted for present purposes.

It is noted that $\mathrm{PB} / 6$ can also be indirectly estimated from equation (6) as $\mathrm{PB} / 6=\mathrm{PR}\left(1 / k_{\mathrm{P}}-7 / 6\right)$. The harmonic mean of $k_{\mathrm{P}}$ for twenty-two pig experiments with average live mass of $49.8 \mathrm{~kg}$ is $k_{\mathrm{P}}=0.525^{(10)}$. For comparable average live mass, seven sex/breed combinations ${ }^{(11)}$ give $\mathrm{PR}=3.4 \mathrm{MJ} / \mathrm{d}$, on average. Accepting this as fairly representative, from equation (6):

$$
\begin{aligned}
\mathrm{PB} / 6 & =3 \cdot 4(1 / 0 \cdot 525-7 / 6) /(48 \cdot 9)^{0.60} \\
& =0.243 \mathrm{MJ} / \mathrm{kg} W^{0.60} \text { perd }
\end{aligned}
$$

This is in fair agreement with and not significantly different from equation (11), since the difference of 0.026 is smaller than the $\mathrm{SE}=0.032$ for equation (12).

The agreement between the estimates contained in equations (11) and (12) provides strong support for the validity of the idea that the difference between $k_{\mathrm{P}}$ and the theoretical efficiency of PS is due to the resynthesis of existing body protein.

The value of maintenance efficiency. The value of $k_{\mathrm{M}}$ accepted for conventional growth diets by the $\mathrm{ARC}^{(2)}$ is $k_{\mathrm{M}}=0 \cdot 81$. The maximum estimate from fourteen diets, widely different in chemical composition, mostly formulated for maintenance purposes ${ }^{(12)}$, is in agreement with the $\mathrm{ARC}^{(2)}$ :

$$
k_{\mathrm{M}}=0 \cdot 807 \text {. }
$$

As the average of a sample of mainly maintenance diets would be too low, equation (13) represents the value accepted for growth diets in the present paper.

\section{Maintenance from fasting heat production}

An overlap of breeds ${ }^{(11,13)}$, together with common experimental procedures of the Station de Recherches Porcines (Saint-Gilles, France), allow meaningful comparisons between the estimates obtained from equations (9) and (10) in Table 1.

Large Whites. No significant difference was observed ${ }^{(13)}$ for the difference between castrates and males, so that the average resting fasting metabolism for Large Whites is fasting HP $=0.990$ $\mathrm{MJ} / \mathrm{kg} W^{0.60}$. To make the estimates between equations (9) and (10) comparable, an estimate for activity was added of $0.0485^{(13)}$ of the total fasting $\mathrm{HP}$ (fasting $\mathrm{HP}=$ resting fasting $\mathrm{HP}+$ activity $\mathrm{HP})$. This gives $\mathrm{IM}_{\mathrm{H}}=(0 \cdot 990+0 \cdot 050) /$ $0.807=1.289 \mathrm{MJ} / \mathrm{kg} W^{060}$ per $\mathrm{d}$.

No sex differences exist in the maintenance INT between different sexes of Large Whites, so that they average INT = $1.068 \mathrm{MJ} / \mathrm{kg} W^{060}$ per $\mathrm{d}^{(11)}$. Hence, from equations (9) and (11) $\mathrm{IM}_{\mathrm{I}}=1.068+0.217=1.285 \mathrm{MJ} / \mathrm{kg} W^{0.60}$ per d, giving excellent agreement between $\mathrm{IM}_{\mathrm{H}}$ and $\mathrm{IM}_{\mathrm{I}}$.

Pietrain and Meishan pigs. The estimates for Pietrain males and Meishan castrates in Table 1 are obtainable from the same sources ${ }^{(11,13)}$ and in the same fashion as for Large Whites. Similar to Large Whites, the two Pietrain estimates in Table 1 are in excellent agreement. In the following the possible reasons for the Meishan discrepancy will be explored.

Meishan discrepancy. van Milgen et al. ${ }^{(13)}$ noted that their estimate of Meishan resting fasting $\mathrm{HP}$ of $0.660 \mathrm{MJ} / \mathrm{kg}$ $W^{060}$ per d was markedly lower than $0.749 \mathrm{MJ} / \mathrm{kg} W^{0.60}$ per $\mathrm{d}$, obtained on similar pigs, in an earlier study ${ }^{(14)}$. Including a correction for movement ${ }^{(13)}$, the Bernier et al. ${ }^{(14)}$ estimate is $0.817 \mathrm{MJ} / \mathrm{kg} W^{0.60}$ per $\mathrm{d}$, relatively near to other estimates $^{(15,16)}$ of 0.842 and $0 \cdot 888$, respectively. The weighted combined estimate ${ }^{(14-16)}$ is $0.848 \mathrm{MJ} / \mathrm{kg} W^{0.60}$ per d. This gives $\mathrm{IM}_{\mathrm{H}}=0 \cdot 848 / 0 \cdot 807=1 \cdot 051 \mathrm{MJ} / \mathrm{kg} W^{060}$ per $\mathrm{d}$.

For comparable body mass, Meishan castrates have much lower proportions of muscle mass to empty body mass than Large White castrates ${ }^{(11)}$. Taking muscle and viscera together, the Meishan:Large White muscle + viscera ratio is 0.717 . Correcting equation (11) with this ratio for the lesser protein content of Meishans, $\mathrm{PB} / 6=0.156 \mathrm{MJ} / \mathrm{kg} W^{0.60}$ per $\mathrm{d}$ is obtained. This can be combined with the INT value for Meishan castrates ${ }^{(11)}$ to give $\mathrm{IM}_{\mathrm{I}}=0.936+0.156=1.092 \mathrm{MJ} / \mathrm{kg} W^{0.60}$ per $\mathrm{d}$. This body composition-corrected estimate of $\mathrm{IM}_{\mathrm{I}}$ is in reasonable agreement with the estimate of $\mathrm{IM}_{\mathrm{H}}$ from the previous paragraph. Hence there is conjecture that the Meishan discrepancy in Table 1 is mainly due to a fasting sensitivity to environmental circumstances of the breed, together with an inapplicable scaling of breakdown rate in relation to body mass, derived for Western pigs.

The average pig. Evidence has been provided for the virtual identity of $\mathrm{IM}_{\mathrm{I}}$ in equation (9) and $\mathrm{IM}_{\mathrm{H}}$ in equation (10) on Large Whites and Pietrains (Table 1), together with a sizeable discrepancy for Chinese Meishan pigs. It is, therefore, of interest to enquire if equations (9) and (10) can be assumed identical for the average Western pig. Provided that HP due to residual digestive and absorptive processes can be accounted for, a short duration of fasting is probably more representative for the producing animal than long-term fasting. van Milgen et al. ${ }^{(13)}$ cite evidence for a rapid decrease in HP during day 1 of fasting, followed by a more gradual decrease afterwards. This gradual decrease in HP is probably due to changes in the mass of portal-drained viscera and the liver and represents, therefore, an abnormal physiological state for a normally growing animal ${ }^{(13)}$. Hence, the resting fasting heat production used in the construction of Table 1 was $24 \mathrm{~h}$ for $25 \mathrm{~kg}$ pigs and $30 \mathrm{~h}$ for 40 and $60 \mathrm{~kg}$ pigs $^{(13)}$. Therefore, all references with unadjusted fasting periods of 30 h or less $^{(13)}$ were used in the construction of Table 2.

Since both breed and type of pig as well as experimental circumstances are important determinants of fasting HP, the 
observations are listed according to these criteria. This seems the best available way of obtaining as representative a sample of Western pigs as possible. The average total fasting $\mathrm{HP}$ in Table 2 is 0.864 ; this gives $\mathrm{IM}_{\mathrm{H}}=0.864$ / $0.807=1.071 \mathrm{MJ} / \mathrm{kg} W^{060}$ per d.

To obtain a representative INT value for equation (9), the INT in Table $1.12^{(2)}$ in $\mathrm{MJ} / \mathrm{kg} W^{075}$ is transformed to $\mathrm{MJ} / \mathrm{kg} W^{060}$ by use of live body masses at the midpoint of the indicated body mass interval. This gives a mean value of INT $=0.852 \mathrm{MJ} / \mathrm{kg} W^{060}(\mathrm{SE} 0.027 ; n$ 11). Together with equation (11), $\mathrm{IM}_{\mathrm{I}}=1.069 \mathrm{MJ} / \mathrm{kg} W^{060}$ per $\mathrm{d}$ is obtained, almost identical to $\mathrm{IM}_{\mathrm{H}}$ for the average Western pig.

\section{Calculating the theoretical efficiency of fat synthesis}

The theoretical efficiency of fat synthesis can be calculated from regression equations for digestible energy (DE) and ME given in Table $3^{(17)}$. The energy values contained in the regression coefficients were obtained from the energy values of sixty-one diets measured in $45 \mathrm{~kg}$ growing Large White boars. For example, the ME potentially available from $1 \mathrm{~kg}$ DM of a diet with $428 \mathrm{~g} \mathrm{DM}$ starch $/ \mathrm{kg}$ would be $17.49 \times 428=7486 \mathrm{~kJ} / \mathrm{kg} \mathrm{DM}$. Most of the coefficients in Table 3 are exactly the same as in the original ${ }^{(17)}$, except those for retained digestible crude protein (CP) and energy metabolisable CP. Both can be obtained as follows. It is assumed that the energy contribution of retained digestible $\mathrm{CP}$ to $\mathrm{ME}$ is the same as digestible $\mathrm{CP}$ to DE. Since the decline in the contribution of digestible $\mathrm{CP}$ from $\mathrm{DE}$ to $\mathrm{ME}$ is due to urinary energy loss, $z$ is solved in the equation:

$$
23.01 \times 0.539+z \times 0.461=20.04,
$$

where the meaning of 23.01 and 20.04 is given in Table 3, and 0.539 and 0.461 are the average proportions of retained digestible $\mathrm{CP}$ and energy metabolisable $\mathrm{CP}$ in the diets ${ }^{(17)}$. A regression coefficient for energy metabolisable $\mathrm{CP}$ is obtained: $z=16 \cdot 57(\mathrm{MJ} / \mathrm{kg})$.

The difference between DE- and ME-associated regression coefficients of $23 \cdot 01-16 \cdot 57=6.44$ must be due to energy loss in the urine coincident with the excretion of $\mathrm{N}$-containing substances. The estimate of 6.44 is in reasonable agreement with the value of $7.2 \mathrm{MJ} / \mathrm{kg}$ protein deaminated favoured by Whittemore et al. ${ }^{(18)}$.

Table 2. Fasting metabolism (heat production) in different experiment, type and breed combinations with fasting periods less than $30 \mathrm{~h}$

\begin{tabular}{|c|c|c|}
\hline Reference & Type & $\begin{array}{l}\text { Fasting metabolism } \\
\left(\mathrm{MJ} / \mathrm{kg} W^{0.60} \text { per } \mathrm{d}\right)\end{array}$ \\
\hline Koong et al. ${ }^{(26)}$ & $H(D \times Y)$ & 0.680 \\
\hline Koong et al. ${ }^{(26)}$ & $L(D \times Y)$ & 0.738 \\
\hline Tess et al. ${ }^{(27)}$ & $H(D \times Y)$ & 0.677 \\
\hline Tess et al. ${ }^{(27)}$ & $L(D \times Y)$ & 0.817 \\
\hline Tess et al. ${ }^{(27)}$ & $\mathrm{Ha} \times \mathrm{LW}$ & 0.866 \\
\hline van Milgen et al. ${ }^{(13)}$ & LW & 1.041 \\
\hline van Milgen et al. ${ }^{(13)}$ & $\mathrm{P}$ & 0.992 \\
\hline Yen et al. ${ }^{(15)}$ & $\mathrm{D} \times \mathrm{W}$ & 0.869 \\
\hline Yen et al. ${ }^{(16)}$ & $W \times(D \times W)$ & 0.941 \\
\hline Bernier et al. ${ }^{(14)}$ & LW & 1.015 \\
\hline Average & & 0.864 \\
\hline SE & & 0.043 \\
\hline
\end{tabular}

$W$, live body mass; $\mathrm{H}$, high backfat line; $\mathrm{D}$, Duroc; $\mathrm{Y}$, Yorkshire; $\mathrm{L}$, low backfat line; Ha, Hampshire; LW, Large White; P, Pietrain; W, White.
The ME potentially available for fat synthesis is then obtained by multiplying the ME regression coefficients by the diet composition ( $\mathrm{g} / \mathrm{kg} \mathrm{DM})$. The assumed efficiencies of dietary protein, fat and carbohydrate follow from Baldwin ${ }^{(19)}$ and van Milgen ${ }^{(20)}$ and are in close agreement with those given by Blaxter ${ }^{(5)}$. (Blaxter's ${ }^{(5)}$ values are generally 1 percentage point lower than the others, presumably an allowance for the cost of transport.) The efficiency for fat synthesis from fermented fibre is from Green \& Whittemore ${ }^{(21)}$.

It is necessary to remember that $k_{\mathrm{F}}$ is usually calculated from $\mathrm{ME}$ values. Hence, the efficiency from ME to fat in Table 3 is needed. The efficiency from digestible $\mathrm{CP}$ to body fat is $0.67^{(19)}$. Since the urine $\mathrm{N}$-associated energy loss will be accommodated by use of the ME-regression coefficient, the efficiency from digestible CP to body fat is considered applicable to the energy metabolisable CP-situation in Table 3. This argument is in agreement with the exposition in Whittemore et al. ${ }^{(18)}$, as the urinary excretion cost is also considered by them separately from the deamination cost, which is necessarily included in the efficiency from digestible $\mathrm{CP}$ to fat. The efficiency of digestible ether extract is from Baldwin $^{(19)}$ and van Milgen ${ }^{(20)}$. The efficiency of the carbohydrates in Table 3 is taken to be $0 \cdot 81$, the value calculated for glucose ${ }^{(19,20)}$. The efficiency for $\mathrm{DE}$ to fat for fibre is $0.46^{(21)}$. Hence, assuming a $20 \%$ loss in the form of methane ${ }^{(21)}$, an efficiency of ME to body fat for digestible acid-detergent fibre is obtained of 0.46/0.80 $=0.58$.

The average energy obtained from fermentation can be calculated from methane energy loss, as equal to $303 \mathrm{~kJ} / \mathrm{kg}$ $\mathrm{DM}^{(17)}$. This is only slightly higher than the contribution of $252 \mathrm{~kJ} / \mathrm{kg}$ DM from digestible acid-detergent fibre in Table 3. Therefore, in agreement with the relatively large difference between DE and ME, fibre-derived efficiency is only attributed to digestible acid-detergent fibre in Table 3.

On the simplifying assumption that the energy use for fat synthesis from all sources is equally likely, the total efficiency of fat synthesis of the diet can be obtained from Table 3 by calculation of the arithmetic mean with weights according to the relative amounts of component substrates of ME. This gives a total theoretical efficiency for fat synthesis of $0 \cdot 81$.

Quiniou et al. ${ }^{(22)}$ give enough information on diet composition to allow similar calculations (Table 4) as in Table 3. Digestibilities $^{(17,23)}$ were taken into consideration. The total theoretical efficiency calculated from Table 4, in a similar fashion to Table 3 , is 0.79 .

Comparison with empirical estimates. The estimate of Quiniou et al. ${ }^{(22)}$ by ordinary multiple regression is $k_{\mathrm{F}}=0.81$ (SE 0.02), obviously not significantly different from a theoretically expected synthesis value of 0.79 . Remarkably, the estimate in the model with the smallest $\mathrm{SE}^{(11)}$ is $k_{\mathrm{F}}=0.814$ (SE 0.015), also in acceptable agreement with the estimates in Tables 3 and 4.

In general the estimates of $k_{\mathrm{F}}$ in the literature are very variable. For growing pigs they range from 0.69 to $1.00^{(10)}$, with a harmonic mean $k_{\mathrm{F}}=0.80(\mathrm{SE} 0.020 ; n 21)$, identical to the average of the theoretical values in Tables 3 and 4 .

\section{Combined maintenance, protein and fat retention}

To test the theory in a combined fashion for estimates of energy required for maintenance, protein and fat synthesis 
Table 3. Estimation of the theoretical efficiency of body fat synthesis from the diet averages in the study by Noblet et al. ${ }^{(17)}$

\begin{tabular}{|c|c|c|c|c|c|}
\hline \multirow[b]{2}{*}{ Nutrient } & \multicolumn{2}{|c|}{$\begin{array}{l}\text { Regression coefficients } \\
(\mathrm{MJ} / \mathrm{kg} \mathrm{DM})\end{array}$} & \multicolumn{2}{|c|}{$\begin{array}{l}\text { ME potentially available for fat } \\
\text { synthesis }\end{array}$} & \multirow[b]{2}{*}{ Assumed efficiency } \\
\hline & $\mathrm{DE}$ & ME & $\mathrm{kJ} / \mathrm{kg} \mathrm{DM}$ & Proportion & \\
\hline DCP & $23 \cdot 01$ & $20 \cdot 04$ & - & - & - \\
\hline RDCP & - & 23.01 & - & - & - \\
\hline EMCP & - & $16 \cdot 57$ & 1199 & 0.098 & 0.67 \\
\hline DEE & 38.99 & $39 \cdot 12$ & 1056 & 0.086 & 0.97 \\
\hline Starch & 17.49 & 17.49 & 7486 & 0.611 & 0.81 \\
\hline Sugars & $16 \cdot 86$ & $16 \cdot 61$ & 980 & 0.080 & 0.81 \\
\hline D Hemi & $17 \cdot 37$ & $18 \cdot 12$ & 815 & 0.066 & 0.81 \\
\hline D Res 1 & $18 \cdot 87$ & $17 \cdot 15$ & 463 & 0.038 & 0.81 \\
\hline DADF & 13.68 & 10.08 & 252 & 0.021 & 0.58 \\
\hline Total & - & - & 1225 & 1.000 & 0.81 \\
\hline
\end{tabular}

$\mathrm{ME}$, metabolisable energy; DE, digestible energy; $\mathrm{DCP}$, digestible crude protein; RDCP, retained digestible crude protein; EMCP, energy metabolisable crude protein; $\mathrm{DEE}$, digestible ether extract; D Hemi, digestible neutral-detergent fibre minus digestible acid-detergent fibre; D Res 1 , digestible organic matter minus other nutrients in Table 3 ; DADF, digestible acid-detergent fibre.

an energy balance sheet was constructed (Table 5) from two experiments in the literature ${ }^{(17,22)}$ with enough information on their diets for the calculation of theoretical efficiencies of fat synthesis. Line 1 simply represents the total energy devoted to PS with theoretical efficiency 6/7. The theoretical $\mathrm{k}$-values employed in the calculation of line 2 are from Tables 3 and 4, respectively. The relationship between MEI and $\mathrm{HP}$, both measured in $\mathrm{MJ} / \mathrm{d}$ given by Noblet et al. ${ }^{(17)}$, is $\mathrm{HP}=0.749 W^{060}+0.26 \mathrm{ME}$. Since $\mathrm{MEI}=\mathrm{HP}+\mathrm{ER}$, it follows by substitution that $\mathrm{MEI}=1.012 W^{060}+1.35 \mathrm{ER}$. The INT estimate in Table 5 follows by taking $\mathrm{ER}=0$.

The protein content of feed has a noticeable effect on PB. Hence the value of $\mathrm{PB} / 6$ in line 4 assumed for Noblet et al. ${ }^{(17)}$, with average CP content of $157 \mathrm{~g} / \mathrm{kg} \mathrm{DM}$, is from Reeds et al. ${ }^{(8)}$ with diets of somewhat lower protein content than Fuller et al. ${ }^{(9)}$. The value in line 4 for INT in Quiniou et al. ${ }^{(22)}$ is the average of INT calculated by them from ordinary regression of MEI on PR and FR. The value of $P B / 6$ is from Fuller et al. ${ }^{(9)}$ since the average $\mathrm{CP}$ content of the diets in Quiniou et al. ${ }^{(22)}$ is $246 \mathrm{~g} / \mathrm{kg}$ DM.

The total predicted energy devoted to maintenance, PR and FR is in reasonable agreement with the average observed intakes of both experiments, with relative deviations, (total $\mathrm{ME}$ - observed $\mathrm{ME}$ )/observed $\mathrm{ME}$, near to +0.03 and -0.01 respectively. The average relative deviation is approximately $+0 \cdot 01$.

Table 4. Estimation of the theoretical efficiency of body fat synthesis from the diet averages in the study by Quiniou et al. ${ }^{(22)}$

\begin{tabular}{lccc}
\hline \multicolumn{3}{c}{$\begin{array}{c}\text { ME potentially available for } \\
\text { fat synthesis }\end{array}$} & \\
\cline { 2 - 3 } Nutrients & $\mathrm{kJ} / \mathrm{kg} \mathrm{DM}$ & Proportion & Assumed efficiency \\
\hline EMCP & 2088 & 0.159 & 0.67 \\
DEE & 532 & 0.041 & 0.97 \\
DC & 10319 & 0.786 & 0.81 \\
DADF & 191 & 0.014 & 0.58 \\
Total & 13130 & 1.000 & 0.79 \\
\hline
\end{tabular}

$\mathrm{ME}$, metabolisable energy; EMCP, energy metabolisable crude protein; DEE, digestible ether extract; DC, digestible carbohydrates; DADF, digestible aciddetergent fibre.
The conclusion follows that the theoretical efficiencies of protein and fat synthesis can be incorporated in prediction equations for average MEI with reasonable accuracy.

\section{Accommodating improved pigs}

Chwalibog et al. ${ }^{(24)}$ provide evidence that, presumably due to selection for higher PR and lower body fat content, comparable fasting $\mathrm{HP}$ in Danish Landrace pigs increased from 0.666 to $0.986 \mathrm{MJ} / \mathrm{kg} W^{0.60}$ per d over a 20-year period. As some of the evidence in the present paper is from early work it is, perhaps, important to indicate in which way the present approach might be applicable to improved pigs.

From observations on twelve improved Danish Landrace male castrates ${ }^{(24)}$ maintenance can be estimated by subtraction from MEI of PR and FR divided by estimates of protein and fat synthesis efficiencies respectively (Tables 3 and 4). This gives maintenance $=2 \cdot 097-0 \cdot 273 / 0 \cdot 86-0.417 /$ $0.80=1.258 \mathrm{MJ} / \mathrm{kg} W^{060}$ per d. On day 3 of fasting, HP was $1.062 \mathrm{MJ} / \mathrm{kg} W^{060}$ per d. From equations (10) and (13), this gives maintenance $=1 \cdot 062 / 0 \cdot 81=1 \cdot 311 \mathrm{MJ} / \mathrm{kg} W^{060}$ per $\mathrm{d}$. Besides confirming theory, this reasonable agreement between subtraction and fasting HP maintenance indicates that the essentials of the suggested methods remain applicable to improved pigs. For appropriate estimates of ME requirements the only necessity would be to use applicable estimates of fasting HP.

To accommodate changes in protein content it may be of value to transform (11) to:

$$
\mathrm{PB} / 6=0.562 \mathrm{MJ} / \mathrm{kg} \operatorname{protein}^{0.60} \text { per } \mathrm{d},
$$

from protein $=0.160 \mathrm{~W}$ recommended by the $\mathrm{ARC}^{(2)}$ for pigs at the time of its publication. For situations where estimates of body composition in terms of muscle, viscera and fat are available, van Milgen et al. ${ }^{(13)}$ provide a formula for the estimation of fasting HP that may be able to accommodate changes due to breeding improvement, as the likely causes of differences between types of pigs are taken into consideration.

\section{Discussion}

To understand the conclusions of the present paper one should realise that the results of regression analyses reflect 
Table 5. Energy balance sheets for two experiments (Noblet et al. ${ }^{(17)}$ and Quiniou et al. ${ }^{(22)}$ ) in the literature

\begin{tabular}{|c|c|c|c|c|}
\hline Line & Predicted contribution & Noblet et al. ${ }^{(17)}\left(\mathrm{MJ} / \mathrm{kg} W^{0.60}\right.$ per d) & Quiniou et al. ${ }^{(22)}\left(\mathrm{MJ} / \mathrm{kg} W^{0.60}\right.$ per d) & Average \\
\hline 1 & $7 \mathrm{PR} / 6$ & 0.374 & 0.283 & 0.329 \\
\hline 2 & $\mathrm{FR} / k$ & 0.740 & 0.662 & 0.707 \\
\hline 3 & INT & 1.012 & 0.836 & 0.924 \\
\hline 4 & $\mathrm{~PB} / 6$ & 0.199 & 0.230 & 0.215 \\
\hline 5 & Total & 2.325 & $2 \cdot 011$ & $2 \cdot 168$ \\
\hline 6 & Observed ME intake & $2 \cdot 264$ & 2.034 & $2 \cdot 149$ \\
\hline 7 & Relative deviation & +0.026 & -0.011 & +0.009 \\
\hline
\end{tabular}

correlation rather than causation. This provides the reason why protein regression coefficients include both the costs of synthesis of new protein and the resynthesis of existing body protein. Furthermore, the linear approximation of basically curvilinear relationships depends on the limits of measurement. Confining measurement to intakes reasonably far from maintenance may cause regression INT estimates of maintenance not to agree with fasting HP estimates. Nevertheless, it follows from this exposition that the main difference between causal and regression analysis approaches is in the apportioning of body protein resynthesis costs between maintenance and PR. Hence, it is concluded that, under comparable circumstances, there are two approximately equal estimates of growth energy requirements in pigs. First, total energy requirements can be estimated from maintenance estimated from fasting HP plus retention costs from theoretical efficiencies of protein and fat synthesis. This is in pigs approximately equal to the second possibility of estimation, namely the energy requirement estimated from multiple regression INT maintenance together with $k_{\mathrm{P}}$ and $k_{\mathrm{F}}$ associated with the regression coefficients.

The approximate equality between the two methods opens up the possibility of easier and cheaper ways of estimating growth energy requirements. The estimate of theoretical PS efficiency is $6 / 7$ and theoretical fat synthesis efficiency can easily be calculated from feed composition by the method displayed in Table 3. Also fasts of short duration ${ }^{(13)}$ should be cheaper and easier than the full-scale measurements necessary for the application of multiple regression methods. In cases where body composition can be estimated, maintenance can also be obtained by subtraction of the total cost of new tissue synthesis from intake, quite possibly with increased accuracy of estimation. In addition, the use of the synthesis efficiency of protein in estimates of energy requirements offers relief from the problems associated with feeding level and age-variable $k_{\mathrm{P}}$ indicated by (1).

As the costs of protein and fat synthesis depend on fixed biochemical reactions, there is no scope for breeding improvement in synthesis efficiencies. This leaves breeding for the efficiency of maintenance as the only option for breeding of growth efficiency. That there are possibilities in this direction is shown by the fact that maintenance depends on body composition, which is amenable to change by selection. Furthermore, Luiting ${ }^{(25)}$ provides evidence that efficiency in use of energy for maintenance is heritable and should respond to selection pressures.

\section{Acknowledgements}

There are, as far as I (C. Z. R.) can discern, no conflicts of interest. The motivation for the study was to investigate the possibility of breeding for improved food efficiency. I gratefully received some personal research remuneration from the University of Pretoria.

\section{References}

1. Kielanowski J (1965) Estimates of the energy cost of protein deposition in growing animals. In Energy Metabolism, pp. 13-18 [KL Blaxter, editor]. London: Academic Press.

2. Agricultural Research Council (1981) The Nutrient Requirements of Pigs. Slough, UK: Commonwealth Agricultural Bureaux.

3. Bergen WG \& Merkel RA (1991) Protein accretion. In Growth Regulation in Farm Animals, pp. 169-198 [AM Pearson and TR Dutson, editors]. London: Elsevier Applied Science.

4. Whittemore CT, Green DM \& Knap PW (2001) Technical review of the energy and protein requirements of growing pigs: energy. Anim Sci 73, 199-215.

5. Blaxter KL (1989) Energy Metabolism in Animals and Man. Cambridge, UK: Cambridge University Press.

6. Roux CZ (2005) Incorporating turn-over in whole body protein retention efficiency in pigs. Anim Sci 80, 71-81.

7. Roux CZ (2006) Incorporating turnover in estimates of protein retention efficiency for different body tissues. Br J Nutr 95, 246-254.

8. Reeds PJ, Fuller MF, Cadenhead A, Lobley GE \& McDonald JD (1981) Effects of change in the intakes of protein and non-protein energy on whole-body protein turnover in growing pigs. Br J Nutr 45, 539-546.

9. Fuller MF, Reeds PJ, Cadenhead A \& Seve B (1987) Effects of the amount and quality of dietary protein on nitrogen metabolism and protein turnover of pigs. Br J Nutr 58, 287-300.

10. Klein M \& Hoffmann L (1989) Bioenergetics of protein retention. In Protein Metabolism in Farm Animals, pp. 404-440 [HD Bock, BO Eggum, AG Low and T Zebrowska, editors]. Oxford: Oxford University Press.

11. Noblet J, Karege C, Dubois S \& van Milgen J (1999) Metabolic utilization of energy and maintenance requirements in growing pigs: effects of sex and genotype. J Anim Sci 77, 1208-1216.

12. Noblet J, Shi XS \& Dubios S (1993) Metabolic utilization of dietary energy and nutrients for maintenance energy requirements in sows: basis for a net energy system. Br J Nutr 70, 407-419.

13. van Milgen J, Bernier JF, Lecozler Y, Dubois S \& Noblet J (1998) Major determinants of fasting heat production and energetic cost of activity in growing pigs of different body weight and breed/castration combination. Br J Nutr 79, 509-517. 
14. Bernier JF, Dubois S \& Noblet J (1996) Fasting heat production of Large White and Meishan growing pigs as influenced by environmental temperature. J Anim Sci 74, Suppl. 1, 180.

15. Yen JT, Nienaber JA, Klindt J \& Crouse JD (1991) Effect of ractopamine on growth, carcass traits and fasting heat production of U.S. contemporary crossbred and Chinese Meishan pure and crossbred pigs. J Anim Sci 69, 4810-4822.

16. Yen JT, Hansen JA, Nienaber JA \& Nelssen JL (1992) Effects of genotype, porcine somatotropin and salbutamol on heat production and visceral weights of pigs. J Anim Sci 20, Suppl. $1,241$.

17. Noblet J, Fortune H, Shi XS \& Dubois S (1994) Prediction of net energy value of feeds for growing pigs. J Anim Sci 72, 344-354.

18. Whittemore CT, Green DM \& Knap PW (2001) Technical review of the energy and protein requirements of growing pigs: protein. Anim Sci 73, 363-373.

19. Baldwin RL (1995) Modeling Ruminant Digestion and Metabolism. London: Chapman and Hall.

20. van Milgen $\mathbf{J}$ (2002) Modeling biochemical aspects of energy metabolism in mammals. J Nutr 132, 3195-3202.

21. Green DM \& Whittemore CT (2003) Architecture of a harmonized model of the growing pig for the determination of dietary net energy and protein requirements and of excretions into the environment (IMS Pig). Anim Sci 77, 113-130.

22. Quiniou N, Dourmad J-Y \& Noblet J (1996) Effect of energy intake on the performance of different types of pig from 45 to $100 \mathrm{~kg}$ body weight. 1. Protein and lipid deposition. Anim Sci 63, 277-288.

23. Noblet J \& Shi XS (1993) Comparative digestibility of energy and nutrients in growing pigs fed ad libitum and adult sows fed at maintenance. Livest Prod Sci 34, 137-152.

24. Chwalibog A, Jakobsen K, Tausen A-H \& Thorbek G (2005) Energy metabolism and nutrient oxidation in young pigs and rats during feeding, starvation and re-feeding. Comp Biochem Physiol A 140, 299-307.

25. Luiting $\mathrm{P}$ (1999) The role of genetic variation in feed intake and its physiological aspects: results from selection experiments. In Regulation of Feed Intake, pp. 75-88 [D van der Heide, EA Huisman, E Kanis and JWM Osse, editors]. Wallingford, UK: CABI Publishing.

26. Koong LJ, Nienaber JA \& Mersmann HJ (1983) Effect of plane of nutrition on organ size and fasting heat production in genetically obese and lean pigs. J Nutr 133, 1626-1631.

27. Tess MW, Dickerson GE, Nienaber JA \& Ferrell CL (1984) The effects of body composition on fasting heat production in pigs. J Anim Sci 58, 99-110. 